\title{
Herquline B, a New Platelet Aggregation Inhibitor Produced by Penicillium herquei Fg-372
}

\author{
Yumi Enomoto, Kazuro Shiomi, Masahiko Hayashi, Rokuro Masuma, \\ Tomoya Kawakubo, Keitchi Tomosawa, Yuzuru IwaI \\ and SATOSHI OMURA*
}

Research Center for Biological Function, The Kitasato Institute, 5-9-1 Shirokane, Minato-ku, Tokyo 108, Japan

(Received for publication September 8, 1995)

\begin{abstract}
A new herquline analog, herquline B was isolated from the culture broth of Penicillium herquei Fg-372. Herquline B contains one piperazine and two cyclohexenones. The pyrrolidine ring of herquline $\mathrm{A}$ was cleaved to yield herquline $\mathrm{B}$. The $\mathrm{IC}_{50}$ value of herquline $\mathrm{B}$ against platelet aggregation induced by ADP and platelet-activating factor were 1.6 and $5.0 \mu \mathrm{M}$, respectively.
\end{abstract}

Herquline (1, Fig. 1) was discovered as an alkaloid from microorganisms by our group and showed weak inhibitory activity against platelet aggregation induced by ADP. ${ }^{1,2)}$ In the course of screening for another alkaloid from the culture broth of herquline producing strain, Penicillium herquei Fg-372, we found a new herquline analog, herquline B (2). Now we renamed 1 herquline $\mathrm{A}$. The structure elucidation revealed that the pyrrolidine ring of $\mathbf{1}$ was cleaved to yield $\mathbf{2}$. Compound $\mathbf{2}$ inhibited platelet aggregation stronger than $\mathbf{1}$.

Here, we report the production, isolation, physicochemical properties, structure elucidation, and biological activities of 2 .

\section{Materials and Methods}

\section{General}

NMR spectra were obtained with a Valian Unity 400 spectrometer. Mass spectrometry was conducted on a JEOL JMS-AX505 HA spectrometer. UV and IR spectra were measured with a Shimadzu UV-240 spectrophotometer and a Horiba FT-210 Fourier transform infrared

Fig. 1. Structures of herqulines A (1) and B (2).

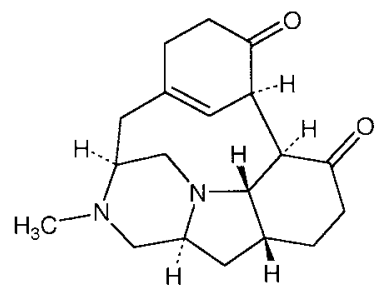

Herquline A (1)

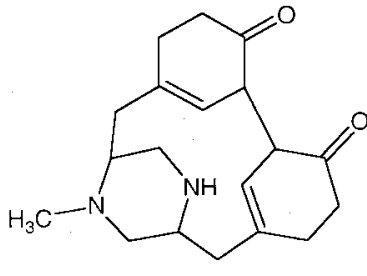

Herquline B (2) spectrometer, respectively. Optical rotation was recorded on a JASCO model DIP-181 polarimeter. Melting point was measured with a Yanaco micro melting point apparatus MP-S3.

\section{Media}

The seed medium was composed of glucose $2.0 \%$, yeast extract $0.2 \%, \mathrm{MgSO}_{4} \cdot 7 \mathrm{H}_{2} \mathrm{O} 0.05 \%$, Polypepton $0.5 \%$, $\mathrm{K}_{2} \mathrm{HPO}_{4} 0.1 \%$, agar $0.1 \%$ in distilled water. The $\mathrm{pH}$ was adjusted to $5.6 \sim 5.8$. The production medium was composed of maltose $2.0 \%$, glucose $0.1 \%$, ammonium acetate $0.5 \%, \mathrm{NaNO}_{3} 0.2 \%, \mathrm{~K}_{2} \mathrm{HPO}_{4} 0.1 \%, \mathrm{MgSO}_{4}$. $7 \mathrm{H}_{2} \mathrm{O} 0.05 \%, \mathrm{KCl} 0.05 \%, \mathrm{FeSO}_{4} \cdot 7 \mathrm{H}_{2} \mathrm{O} 0.01 \%$, yeast extract $0.2 \%$, agar $0.1 \%$. The $\mathrm{pH}$ was adjusted to 6.0 prior to sterilization.

Assay for Platelet Aggregation

The inhibitory activity against platelet aggregation was assayed using platelet rich plasma (PRP) from citrated-rabbit blood. PRP $(90 \mu \mathrm{l})$ was placed in a 96-well plate and preincubated at $37^{\circ} \mathrm{C}$ for 5 minutes. Five $\mu$ of 1 or 2 was added to the PRP. After 3 minutes preincubation, the reaction was started by adding plateletactivating factor (PAF, $0.3 \mu \mathrm{M}$ ) or ADP $(12.5 \mu \mathrm{M})$ as a platelet aggregating agent. The aggregation was measured, with frequently mixing, at $520 \mathrm{~nm}$ by Titertek Multiskan (Dainippon Pharmaceutical Co., Ltd., Osaka) at 1 minute intervals.

Antimicrobial Activity

Antimicrobial activity was tested for 14 species of microorganisms. An agar plate containing each microorganism put on $6-\mathrm{mm}$ paper disk containing $50 \mu \mathrm{g}$ of samples was incubated for $24 \sim 48$ hours at $27^{\circ} \mathrm{C}$ or $37^{\circ} \mathrm{C}$, on each appropriate condition. Then antimicrobial activity was estimated by measuring the diameter of inhibitory zone. 


\section{Results and Discussion}

Taxonomy of the Producing Organism Fg-372

Strain Fg-372 was originally isolated from a soil sample collected at Saitama Prefecture, Japan. For identification of fungus, CzAPEK's agar, malt extract agar and potatodextrose agar were used. This strain grew restrictedly to form sage green to pea green colonies with diameter of $10 \sim 25 \mathrm{~mm}$ after incubation for 7 days at $27^{\circ} \mathrm{C}$. Growth at $37^{\circ} \mathrm{C}$ was very poor in these media. The colony surface was velvety. The colors of the reverse side of the colony and soluble pigment were gold to dusty yellow. When the strain Fg-372 was grown on potato-dextrose agar at $27^{\circ} \mathrm{C}$ for 7 days, the conidiophores were bone from substrate hyphae, and the penicillia were biverticillate and usually symmetrical as shown in Fig. 2 . The phialides were $9 \sim 10 \times 2.5 \sim 3.5 \mu \mathrm{m}$, and its surface was smooth.

From the above characteristics, the strain Fg-372 was identified as the Penicillium herquei ${ }^{3)}$ and named Penicillium herquei Fg-372. This strain was deposited at the National Institute of Bioscience and HumanTechnology, Agency of Industrial Science and Technology, Japan, as FERM P-14760.

\section{Production and Isolation}

The medium reported previously ${ }^{1)}$ did not produce 1 by submerged culture. We examined various media for the production of $\mathbf{1}$ and a new production medium was found to produce 1 by submerged culture. Therefore minor analog could be obtained easier than before. Compound 2 was produced in the culture broth of both media. In the course of testing media, the production of 1 increased when tyrosine was added. It suggests that

Fig. 2. Scanning electron micrograph of penicillia of strain $\mathrm{Fg}-372$.

\section{Bar represents $5 \mu \mathrm{m}$}

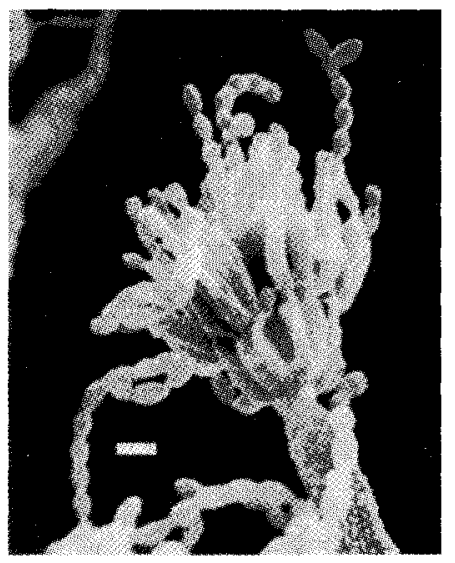

tyrosine is a biosynthetic precursor of $\mathbf{1}$.

The stock culture of the strain Fg-372 was inoculated into two $500-\mathrm{ml}$ Erlenmeyer flasks containing $100 \mathrm{ml}$ of the seed medium and the flasks were incubated on a rotary shaker at $27^{\circ} \mathrm{C}$ for 2 days. Then $200 \mathrm{ml}$ of the seed culture was transferred into a 30 -liter jar fermenter containing 20 liters of the production medium. The fermentation was carried out at $27^{\circ} \mathrm{C}$ for 7 days with aeration of 10 liters/minute and agitation of $250 \mathrm{rpm}$.

The isolation of herqulines was guided by Dragendorff reagent on TLC.

Acetone was added to whole broth (20 liters) and the mixture was stirred. After filtration, the acetone extract was evaporated to remove acetone. Residual solution was adjusted to $\mathrm{pH} 10$ with $\mathrm{NH}_{4} \mathrm{OH}$ and herqulines were extracted with $\mathrm{CHCl}_{3}$. Then they were transferred into $0.1 \mathrm{~N} \mathrm{HCl}$ aqueous solution. The water layer was adjusted to $\mathrm{pH} 10$ again and they were extracted with $\mathrm{CHCl}_{3}$. The $\mathrm{CHCl}_{3}$ extract was concentrated to dryness to give a yellow oil $(456 \mathrm{mg})$. The oil was dissolved in a small volume of $\mathrm{CHCl}_{3}$ and applied on a column of $\mathrm{NH}_{2}$-silica gel (Chromatorex NH-DM1020, Fuji Silysia Chemical, $20 \mathrm{~g})$ prepared with hexane - ethyl acetate $(95: 5)$. The column was eluted stepwise with hexane - ethyl acetate $(90: 10,80: 20$, and $0: 100)$ and methanol. The eluate from hexane - ethyl acetate $(80: 20)$ was concentrated and further purified by silica gel column to give a white powder of $1(108 \mathrm{mg})$. The fractions that were eluted with methanol and exhibited positive Dragendorff reagent in $\mathrm{NH}_{2}$-silica gel were combined and concentrated to give $43.4 \mathrm{mg}$ of yellow oil. It was dissolved in $\mathrm{CHCl}_{3}$, applied on a silica gel column ( $2 \mathrm{~g}$, Wakogel C-300, Wako Pure Chemical Ind.), and eluted with $\mathrm{CHCl}_{3}$ - methanol (20:1 and $10: 1)$. The eluate from $\mathrm{CHCl}_{3}-$ methanol $(10: 1)$ was concentrated to give $11.1 \mathrm{mg}$ of yellow oil. It was applied onto a silica gel TLC (Kieselgel $60 \mathrm{~F}_{254}$, Merck) and developed with $\mathrm{CHCl}_{3}$-methanol $(8: 1)$. The zone that showed positive Dragendorff reagent was collected and

Table 1. Physico-chemical properties of 2.

\begin{tabular}{|c|c|}
\hline Appearance & White powder \\
\hline $\mathrm{MP}\left({ }^{\circ} \mathrm{C}\right)$ & $109 \sim 1.13$ \\
\hline$|\alpha|_{D}^{25}$ & $-85.2(c 0.3, \mathrm{MeOH})$ \\
\hline Molecular formula & $\mathrm{C}_{19} \mathrm{H}_{26} \mathrm{~N}_{2} \mathrm{O}_{2}$ \\
\hline FD-MS $(m / z)$ & $315(\mathrm{M}+\mathrm{H})^{+}$ \\
\hline $\begin{array}{r}\text { HR FAB-MS: calcd } \\
\text { found }\end{array}$ & $\begin{array}{l}315.2074\left(\mathrm{C}_{19} \mathrm{H}_{27} \mathrm{~N}_{2} \mathrm{O}_{2}\right) \\
315.2060(\mathrm{M}+\mathrm{H})^{+}\end{array}$ \\
\hline $\mathrm{UV} \lambda_{\max }^{\mathrm{MeOH}} \mathrm{nm}(\varepsilon)$ & $203(9100), 222(\mathrm{sh}, 1530), 285(780)$ \\
\hline $\mathrm{IR} v_{\max }(\mathrm{KBr}) \mathrm{cm}^{-1}$ & $3400,2920,1650,1540,1110$ \\
\hline Solubility: soluble & $\mathrm{MeOH}, \mathrm{CHCl}_{3}$ \\
\hline insoluble & $\mathrm{H}_{2} \mathrm{O}$, benzene, ethyl acetate \\
\hline
\end{tabular}


Table 2. The ${ }^{1} \mathrm{H}$ and ${ }^{13} \mathrm{C}$ NMR data of 1 and 2 .

\begin{tabular}{|c|c|c|c|c|}
\hline \multirow[b]{2}{*}{ Position } & \multicolumn{2}{|r|}{1} & \multicolumn{2}{|r|}{2} \\
\hline & ${ }^{13} \mathrm{C}$ & ${ }^{L} \mathrm{H}$ & ${ }^{13} \mathrm{C}$ & ${ }^{1} \mathrm{H}$ \\
\hline 1 & $38.7 \mathrm{t}$ & $1.82 \mathrm{~m}(1 \mathrm{H}), 1.97 \mathrm{~m}(1 \mathrm{H})$ & $41.7 \mathrm{t}$ & $2.28 \mathrm{~m}(1 \mathrm{H}), 2.56 \mathrm{~m}(1 \mathrm{H})$ \\
\hline 2 & $56.1 \mathrm{~d}$ & $3.42 \mathrm{~m}(1 \mathrm{H})$ & $51.6 \mathrm{~d}$ & $3.25 \mathrm{~m}(1 \mathrm{H})$ \\
\hline 4 & $43.2 \mathrm{t}$ & $\begin{array}{l}2.95 \mathrm{dd}(1 \mathrm{H}, \mathrm{J}=7.5,15.5 \mathrm{~Hz}) \\
3.02 \mathrm{dd}(1 \mathrm{H}, \mathrm{J}=2,15.5 \mathrm{~Hz})\end{array}$ & $44.8 \mathrm{t}$ & $\begin{array}{l}2.92 \mathrm{dd}(1 \mathrm{H}, \mathrm{J}=5,14 \mathrm{~Hz}) \\
3.0 \mathrm{ldd}(1 \mathrm{H}, \mathrm{J}=3,14 \mathrm{~Hz})\end{array}$ \\
\hline 5 & $67.2 \mathrm{~d}$ & $2.40 \mathrm{~m}(1 \mathrm{H})$ & $59.1 \mathrm{~d}$ & $2.41 \mathrm{~m}(1 \mathrm{H})$ \\
\hline 6 & $38.1 \mathrm{t}$ & $\begin{array}{l}2.03 \mathrm{dd}(1 \mathrm{H}, \mathrm{J}=3,13.5 \mathrm{~Hz}) \\
2.60 \mathrm{dd}(1 \mathrm{H}, \mathrm{J}=2,13.5 \mathrm{~Hz})\end{array}$ & $37.0 \mathrm{t}$ & $\begin{array}{l}1.78 \mathrm{dd}(1 \mathrm{H}, \mathrm{J}=4,14.5 \mathrm{~Hz}) \\
2.73 \mathrm{brd}(1 \mathrm{H}, \mathrm{J}=14.5 \mathrm{~Hz})\end{array}$ \\
\hline 7 & $141.4 \mathrm{~s}$ & & $135.7 \mathrm{~s}$ & \\
\hline 8 & $32.0 \mathrm{t}$ & $2.43 \mathrm{~m}(1 \mathrm{H}), 2.78 \mathrm{~m}(1 \mathrm{H})$ & $33.2 \mathrm{t}$ & $2.48 \mathrm{~m}(1 \mathrm{H}), 2.68 \mathrm{~m}(\mathrm{lH})$ \\
\hline 9 & $39.9 \mathrm{t}$ & $\begin{array}{l}2.35 \mathrm{dd}(1 \mathrm{H}, \mathrm{J}=2,13 \mathrm{~Hz}) \\
2.52 \mathrm{dd}(1 \mathrm{H}, \mathrm{J}=6,13 \mathrm{~Hz})\end{array}$ & $39.4 t$ & $2.48 \mathrm{~m}(\mathrm{lH}), 2.67 \mathrm{~m}(\mathrm{lH})$ \\
\hline 10 & $212.5 \mathrm{~s}$ & & $209.8 \mathrm{~s}$ & \\
\hline 11 & $51.7 \mathrm{~d}$ & $3.95 \mathrm{~m}(1 \mathrm{H})$ & $50.9 \mathrm{~d}$ & $3.95 \mathrm{~m}(1 \mathrm{H})$ \\
\hline $11 \mathrm{a}$ & $55.5 \mathrm{~d}$ & $1.87 \mathrm{dd}(1 \mathrm{H}, \mathrm{J}=2,5 \mathrm{~Hz})$ & $48.9 \mathrm{~d}$ & $3.80 \mathrm{~m}(1 \mathrm{H})$ \\
\hline 12 & $211.6 \mathrm{~s}$ & & $211.9 \mathrm{~s}$ & \\
\hline 13 & $39.3 \mathrm{t}$ & $2.45 \mathrm{~m}(2 \mathrm{H})$ & $39.7 \mathrm{t}$ & $2.48 \mathrm{~m}(1 \mathrm{H}), 2.68 \mathrm{~m}(1 \mathrm{H})$ \\
\hline 14 & $25.5 \mathrm{t}$ & $1.57 \mathrm{~m}(1 \mathrm{H}), 1.86 \mathrm{~m}(1 \mathrm{H})$ & $30.8 \mathrm{t}$ & $2.32 \mathrm{~m}(1 \mathrm{H}), 2.61 \mathrm{~m}(1 \mathrm{H})$ \\
\hline $14 \mathrm{a}$ & $38.5 \mathrm{~d}$ & $1.93 \mathrm{~m}(1 \mathrm{H})$ & $138.3 \mathrm{~s}$ & \\
\hline $14 \mathrm{~b}$ & $63.1 \mathrm{~d}$ & $2.71 \mathrm{~d}(1 \mathrm{H}, \mathrm{J}=5 \mathrm{~Hz})$ & $124.8 \mathrm{~d}$ & $5.31 \mathrm{~m}(1 \mathrm{H})$ \\
\hline 15 & $125.1 \mathrm{~d}$ & $5.60 \mathrm{~d}(1 \mathrm{H}, J=1.5 \mathrm{~Hz})$ & $127.2 \mathrm{~d}$ & $5.25 \mathrm{~m}(1 \mathrm{H})$ \\
\hline 16-Me & $43.4 \mathrm{q}$ & $2.17 \mathrm{~s}(3 \mathrm{H})$ & $42.9 \mathrm{q}$ & $2.26 \mathrm{~s}(3 \mathrm{H})$ \\
\hline 17 & $61.6 \mathrm{t}$ & $\begin{array}{l}2.22 \mathrm{dd}(1 \mathrm{H}, \mathrm{J}=1,12 \mathrm{~Hz}) \\
2.25 \mathrm{dd}(1 \mathrm{H}, \mathrm{J}=5.5,12 \mathrm{~Hz})\end{array}$ & $53.2 \mathrm{t}$ & $2.57 \mathrm{~m}(2 \mathrm{H})$ \\
\hline
\end{tabular}

The $\mathrm{CDCl}_{3}$ signals (7.26 ppm of ${ }^{1} \mathrm{H}$ and $77.0 \mathrm{ppm}$ of ${ }^{13} \mathrm{C}$ ) were used as references. The coupling constants $(\mathrm{Hz})$ are in parentheses.

extracted with methanol. The methanol extract was concentrated and subjected to reverse phase HPLC under the following conditions: column, Asahipak ODP-50 (i.d. $21.5 \times 300 \mathrm{~mm}$, Asahi Chemical Ind.); mobile phase, $\mathrm{CH}_{3} \mathrm{CN}-12.5 \mathrm{~mm}$ sodium borate ( $\mathrm{pH} 10$ ) buffer (40:60); flow rate, $3 \mathrm{ml} / \mathrm{minute}$; detection, UV $220 \mathrm{~nm}$. Under these conditions, the peak eluted at 15 minutes was collected to yield a white powder of $2(5.2 \mathrm{mg})$.

\section{Physico-chemical Properties}

The compound $\mathbf{2}$ was isolated as a white powder. Its physical and chemical properties are summarized in Table 1. The molecular formula of 2 was deduced to be $\mathrm{C}_{19} \mathrm{H}_{26} \mathrm{~N}_{2} \mathrm{O}_{2}$ by HR FAB-MS, which was same as that of 1 .

\section{Structure Elucidation}

The structure of 1 was elucidated on the basis of X-ray crystallographic analysis previously. ${ }^{2)}$ This time, we carried out $1 \mathrm{D}$ and 2D NMR experiments for 1 and accomplished the assignment of the ${ }^{1} \mathrm{H}$ and ${ }^{13} \mathrm{C}$ NMR signals (Table 2).

The structure of $\mathbf{2}$ was elucidated by the NMR spectral analysis. The DEPT and HMQC experiments of $\mathbf{2}$ revealed that 2 contains 1 methyl carbon, 8 methylene carbons, 6 methine carbons including 2 olefinic methines, 2 olefinic quaternary carbons, and 2 carbonyl carbons (Table 2). Comparing with the ${ }^{13} \mathrm{C}$ signals of $\mathbf{2}$ to $\mathbf{1}$, two
Fig. 3. Structure of 2 elucidated by ${ }^{1} \mathrm{H}^{-1}{ }^{-} \mathrm{H}$ COSY and HMBC.

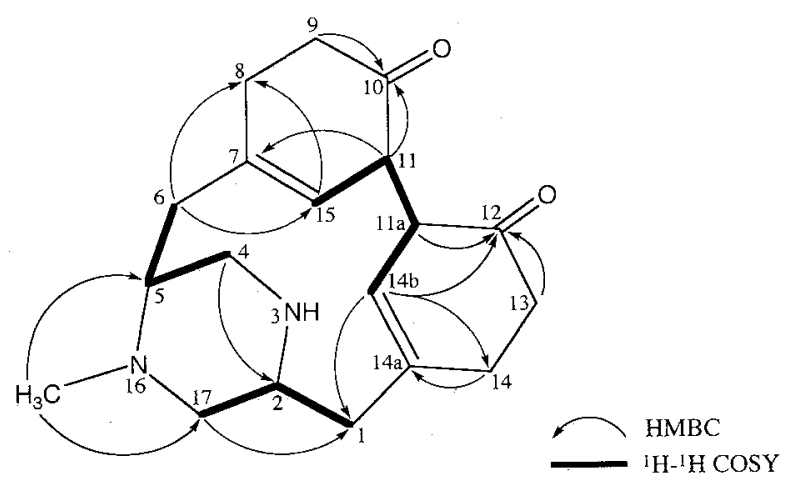

new olefins appeared and two methines disappeared in that of 2. The partial structures of 2 was established by the ${ }^{1} \mathrm{H}^{-1} \mathrm{H}$ COSY and they were pieced together into the final structure on the basis of the long-range coupling observed in the HMBC experiments (Fig. 3). The HMBC experiment indicated that the structure of 2 was same as that of 1, except for N-3, C-14a, and C-14b. An olefinic proton at $\delta 5.31(14 \mathrm{~b}-\mathrm{H})$ was correlated with $\mathrm{C}-1(\delta 38.7)$, C-12 ( $\delta$ 211.9), and C-14 ( $\delta$ 25.5). C-14a ( $\delta$ 138.3) was assigned by the correlation with $14-\mathrm{H}_{2}(\delta 2.32,2.61)$. Therefore, it was suggested that the bond between N-3 and $\mathrm{C}-14 \mathrm{~b}$ of 1 was cleaved and a double bond was 
formed between C-14a and C-14b. Thus, the structure of 2 containing one piperazine and two cyclohexenone rings was elucidated (Fig. 1).

\section{Biological Properties}

\section{Inhibitory Activity of Platelet Aggregation}

The preliminary data suggested that 1 showed a weak inhibition against blood platelet aggregation induced by ADP. ${ }^{1)}$ Here we examined the inhibitory activity of herqulines against platelet aggregation induced by PAF and ADP using PRP from rabbit blood. PAF and ADP caused a submaximal aggregation at $0.3 \mu \mathrm{M}$ and $12.5 \mu \mathrm{M}$ in the assay system, respectively. $\mathrm{IC}_{50}$ values of herqulines were shown in Table 3 . Compound 2 inhibited platelet aggregation stronger than $\mathbf{1}$.

A little change of the structure from $\mathbf{1}$ to $\mathbf{2}$ caused much inhibitory activity against platelet aggregation. Though the inhibitory mechanism is not clear, it may be due to the subcellular reaction because of its nonselective inhibitory mode for PAF- or ADP-induced aggregation. Further investigations are necessary to clarify the inhibitory mechanism of 2 .

Table 3. Inhibitory activity of $\mathbf{1}$ and $\mathbf{2}$ in platelet aggregation.

\begin{tabular}{ccc}
\hline compound & \multicolumn{2}{c}{$\mathrm{IC}_{50}(\mu \mathrm{M})$} \\
& PAF aggregation & ADP aggregation \\
\hline 1 & 240 & 180 \\
2 & 5.0 & 1.6 \\
\hline
\end{tabular}

Antimicrobial Activity

Compound 2 showed no antimicrobial activities at $50 \mu \mathrm{g} /$ disk (paper disk method) against Bacillus subtilis PCI 219, Staphylococcus aureus ATCC 6538p, Micrococcus luteus ATCC 9341, Mycobacterium smegmatis ATCC 607, Escherichia coli NIHJ, Pseudomonas aeruginosa PCI 602, Xanthomonas oryzae KB 88, Bacteroides fragilis ATCC 23745, Acholeplasma laidlawii PG 8, Piricularia oryzae KF 180, Aspergillus niger ATCC 6275, Mucor racemosus IFO 4581, Candida albicans KF 1, and Saccharomyces sake KF 26.

\section{Acknowledgments}

We thank Ms. Noriko SATO of School of Pharmaceutical Sciences, Kitasato University for measurements of NMR spectra, and also thank Ms. AKiko NaKaGawa and Ms. ChIKAKo SAKabe of School of Pharmaceutical Sciences, Kitasato University for measurements of mass spectra. We are grateful to Dr. Toshiaki SunazuKa of School of Pharmaceutical Sciences, Kitasato University for valuable discussion.

\section{References}

1) Òmura, S.; A. Hirano, Y. IwaI \& R. Masuma: Herquline, a new alkaloid produced by Penicillium herquei. Fermentation, isolation and properties. J. Antibiotics 32: $786 \sim 790,1979$

2) Furusaki, A.; T. Matsumoto, H. Ogura, H. TakaYANAGI, A. Hirano \& S. ŌMURA: X-ray crystal structure of herquline, a new biologically active piperazine from Penicillium herquei Fg-372. J. Chem. Soc. Chem. Commun. 1980: 698, 1980

3) Mrnoura, K.: Penicillium herquei Bain. et Sartory. In Kinrui Zukan. II. Ed., S. UDAGAWA et al., pp. 1095 1096, Kodansha, Tokyo, 1978 